Al-Fusha: Arabic Language Education Journal

Vol. 1 No. 2 Juli 2019 | Hal. 9-26

ISSN (Cetak): 2655-6162 | ISSN (Online): 2655-8025

https://ejournal.inaifas.ac.id/index.php/alfusha/article/view/345

\title{
أسلوب المناقشة للمتوفقين \\ في ترقية مهارة الكلام بقواعد اللغة العربية
}

\author{
Ahmad Mizan Rosyadi Abdul Jalil Manan \\ IAI Al-Falah As-Sunniyyah Kencong Jember \\ (ahmadmizan456@gmail.com)
}

\begin{abstract}
Speaking is a basic competance to success for learning language, especially Arabic. In the reality, most of students feel difficulty to make conversation, it is because of monopolized by educators showing up conversation skills and little opportunities for students to participate in learning activities and exersice. Participatory method is one of many methods in learning language that can make students more active in speaking. With quantitative expremental study by using observation, interview, and test, this research will be going to describe (1) participatory methods to improve students pronounciation on the right makhraj and (2) ways to improve vocabularies, Arabic grammar, motivation, and ability conversation.
\end{abstract}

Keywords: participatory, speaking, ability

\section{مقدّمّة}

إنّ وظيفة اللغات تتعاظم يوما بعد يوم مع التقدّم البشـري ولاسـيما في الحضشارة المعاصرة وتكنولوجيا حضارة الاتصال والمواصلات. واللغة العربية لغة حضارة، ولغة رسالة حية وخالدة هي القرآن الكريم المتعبّد بكلماته، واللغة العربية ليست لغة الأمة العربية فقط ولكتّها لغنة العالم.

إن للكلام منزلة كبيرة في حياة الناس، إذ لا يمكن الاستغناء عناه في أي زمن أو مكان، ويعتبر الكام الفن الثاني من فنون اللغة الأربعة بعد الاستماع.' ' أحمد فؤاد عليان، المهارات اللغوية ماهيتها وطرائق تدريسها، طا ، (الرياض:دار السلم، ب999) ص 190. 
ولاشك أن الكلام من أهم ألوان النشاط اللغوى للكبار والصغار على السواء، فالناس يستخدمون الكلام أكثر من الكتابة في حياتهم.' وهو معيار أساسي لنجاح الطلاب في تعلّم

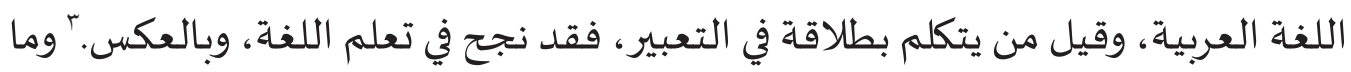
زال تعليم مهارة الكلام يكون تحت سيطرة المعلم ولا يتيح الفرصة لدى الطلاب ليشتركوا بجهد في الأنشطة التعليمية، حتى أن الدارسين لا يستطيعون التكلّم باللغة العربية. ومن

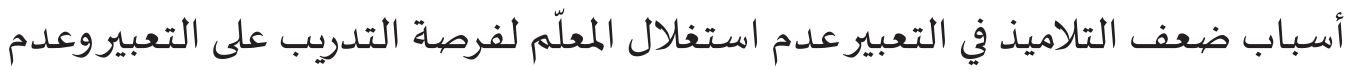
اهتماماء بتوليد الدافع واقتناص الفرصة المطابقة. وبعد فحص الباحث ومشاركته بالتعليم في المدرسة العالياةه السيّنيّة ابكنشـونج - جمبر قد

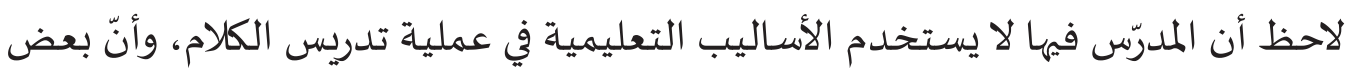
الطلاب لا يشتركون بفعالية في عملية دراسة الكلام، على الرغم من أنّ في هذا المعهد أكثرهم ماهرون في القواعد العربية لأنّ تعلم اللغة العربية فيه على طريقة القواعد والترجمة،

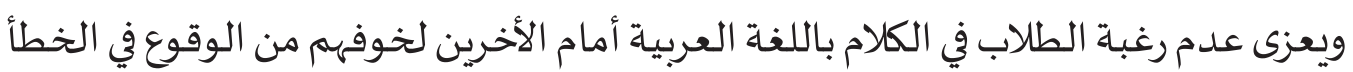
وصعوبة الحصول على الكلمة الصحيحة. إن الدارس يستطيع أن يتعلم جيّدا إذا اشترك اشتراكا نشيطا في كل عملية في حجرة الدراسة وأتيحت له الفرصة لاكتشـاف الأشياء بنفسـه. وإحدى الطرق لاشتراك الدارسين في عملية التعليم هي أسلوب المشاركة بمعنى مشاركة الدارسين في الكلام بطريقة مناقشـة. لأنّ المناقشة من الطرق الفعالة في تدريس اللغة العربية بحيث تنمي معلومات التلاميذ ماتِ وثروتهم اللغوية، وتحثّهم على البحث والاطلاع، وتصلح في جميع المراحل التعليمياة، ولاسيما في الصفوف العليا - وخاصة في المرحلة الثانوية -التي تستخدم أسئلة تتناول جوانب وتئب الموضوع المدروس.

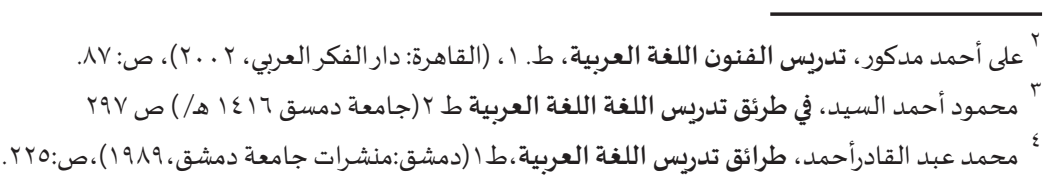
.Nurhadi, dkk, Pembelajaran Kontekstual dan Penerapannya dalam KBK, Malang: Universitas Negeri Malang, 2004, h. $8^{\circ}$

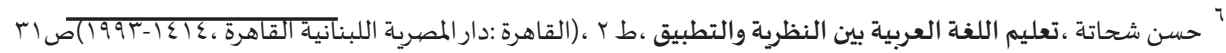




\section{المبحث الأول: مباحث مهارة الكلام}

مفهوم مهارة الكلام

لفظ المهارة مصدر من مهر- يمهر- مهارة بمعنى الحذق والإجادة والمراد فيها الاستطاعة. \ والكلام بمعنى الجملة المركبة المفيدة.^وتعريفها اصطلاحي المنطوق الذي يعبر بهاء المتكلم

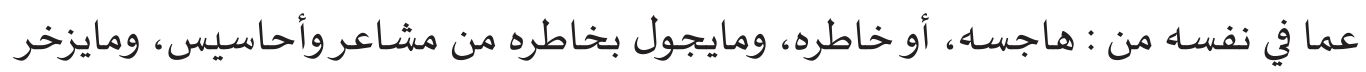

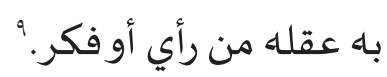
عبّر الناقة عن الكلام هو عنصر اللغة المهم بجوار الاستماع والقراءة والكتابة ويحتلّ الكلام بصفة خاصيّة مركزا هاما في المجتمع الحديث، بل في المجتمع القديم ولقد أبرز الكتاب منذ فئ

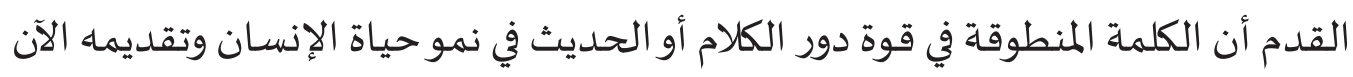

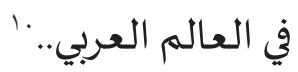
ويمكن تعريف الكلام بأنه ما يصدرعن الإنسان من صوت يعبر باه عن شيئ له دلالة في ذهن

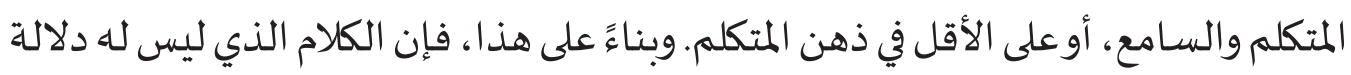
في ذهن المتكلم أو السـامع، لايعد كلاما، بل هي أصيوات لا معنى لها.

\section{أهداف تدريس الكلام}

ا - أن ينطق المتعلم أصوات اللغة العربية ، وأن يؤدي أنواع النبروالتنغيم المختلفة وذلك

$$
\text { بطريقة مقبولة من أبناء العربية. }
$$

r- أن ينطق الأصوات المتجاورة والمتشابهة.

r- أن يدرك الفرق في النطق بين الحركات الطويلة والقصيرة.

ع - أن يعبرعن أفكاره مستخدما الصيخ النحوية المناسبة.

ه- أن يعبرعن أفكاره مستخدما للنظام الصحيح لتركيب الكلمة في العربية خاصية في لغة

الكلام.

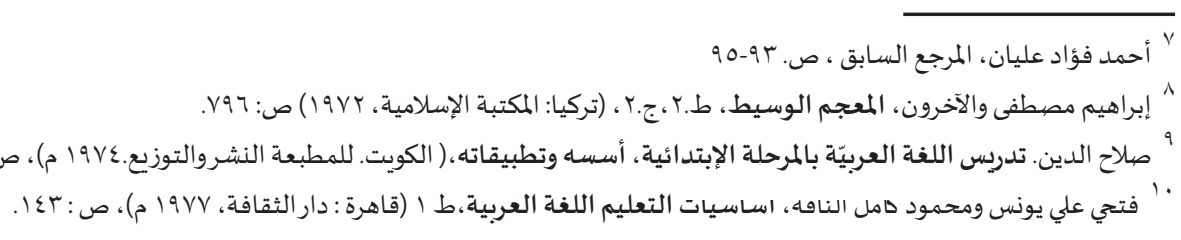

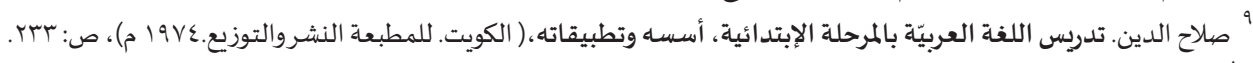


7- أن يستخدم بعض خصائص اللغة في التعبير الشفوي مثل التذكير والتأنيث وتمييز العدد والحال ونظام الفعل وأزمنتاه وغير ذلك مما يلزم المتكلم بالعربية. V - أن يكتسب ثروة لفظية كلامية مناسبة لعمره ومستوى نضجه وقدراته، ᄉ- - أن تستخدم بعض أشكال الثقافية العربية المقبولة والمناسبة لعمره ومستوى

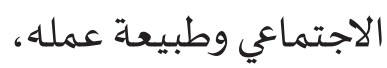

$$
\text { 9- وأن يكتسب بعض المعلومات الأسـاس عن التراث العربي والإسلامي. }
$$

| ا - أن يتمكن من التفكير باللغة العربية والتحدث بها بشكل متصل ومترابط لفترات زمنية مقبولة.

r ا - إن تعليم الكلام باللغة الأجنبية يعدّ أسـاسـا لممارسة كثير من أنشطة الإنسان وتحقيق

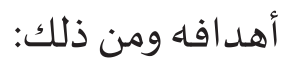

$$
\text { أ) أن تطلب المتعلم شيئا ما. }
$$

ب) أن يستعلم عن الأماكن والأوقات والأشخاص.

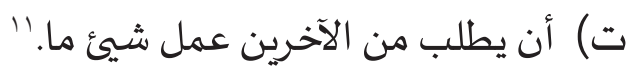

\section{بعض الجوانب المهمة في تعليم الكلام}

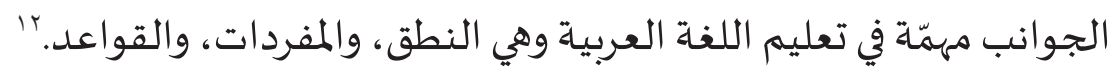

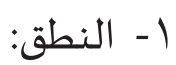

من أهم الجوانب، الجانب الصوتي، إذ يرى التربويون الأهمية الكبرى لتعليم النطق منذ

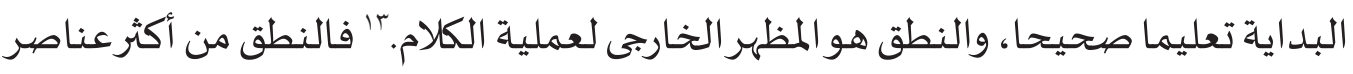
اللغة صعوبة في تغييره أو تصحيحاه بعد تعلّماه بشكل خاطئ. وليكن واضحا في الأذهان أنها " محمود كامل الناقة ورشدي أحمد طعيمة ، طرائق تدريس اللغة العربية لغير الناطقين بها، ط. 1، (منشورات المنظمة الإسلامية للتربية

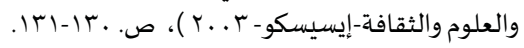

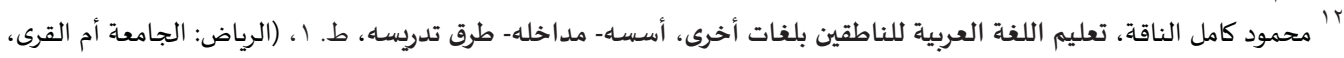

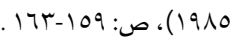
"' على أحمد مدكور، المرجع السابق ، ص: . • 9. 
ليس المطلوب في النطق أن ينطق الدارس بشكل كامل تام.

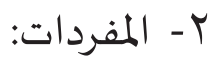

تعد تنمية الثروة اللغوية هدفا من أهداف أي خطة لتعليم لغة أجنبية، ذلك أن المفردات هي أدوات حمل المعنى، كما أهها في ذات الوقت وسائل التفكير، فبالمفردات يستطيع المتكلم أن يفكرثم يترجم فكره إلى كلمات تحمل ما يريد.

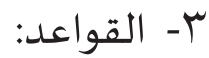

كثيرا ما يهمل المهتمون بتعليم اللغة الأجنبية الإشـارة إلى القواعد، ومهما يكن الأمر فثمة حقيقة لا يمكن إنكارها، وهي أن اللغة تحكمها مجموعة من القواعد التي ينبغي أن يعرفها المتكلم جيّدا، والتي يجب أيضا أن يعرفها الراغب في تعلمها سواء تم ذلك في وقت مبكر أو وقت متأخر، وسواء تم بوعي أوبغيروعي، ونحن إذ نقرر هذا إنما نقرره ونحن واعون تماما

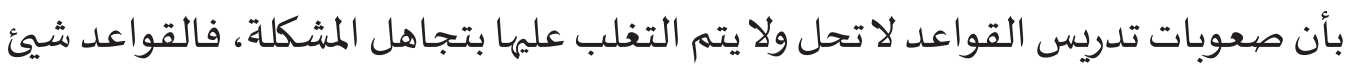
ضروري لتعلم مهارات اللغة.

\section{توجيهات عامّة لتدريس الكلام}

التوجيهات العامة التي قد تسهم في تطويرتدريس مهارة الكلام في العربية كلغة ثانية: 17

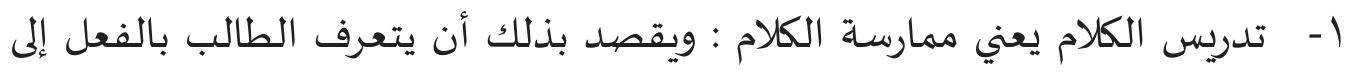

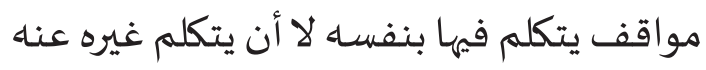

r - أن يعبر الطلاب عن خبرة : يقصد يذلك ألاّ يكلف الطالب بالكلام عن شيئ ليس لدياء علم باء

r- التدريب على توجيه الانتباه : إن الكلام نشاط عقلي مركب. إنه يستلزم القدرة على تمييز الأصوات عند سماعها وعند نطقها. والقدرة على تعرف التراكيب، وكيف أن أن إندان

$$
\text { إختلافها يؤدي إلى اختلاف المعنى. }
$$

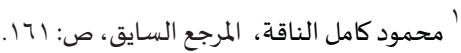

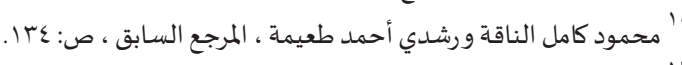

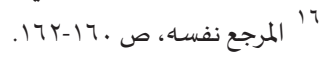


ع- عدم المقاطعة و كثرة التصحيح : من أكثر الأشياء حرجا للمتحدث وإحباطا له أن

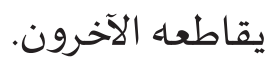

0- مستوى التوقعات :إن الحقيقة التي ينبغي أن يعرفها معلم العربية كلغة ثانية أن تعلم

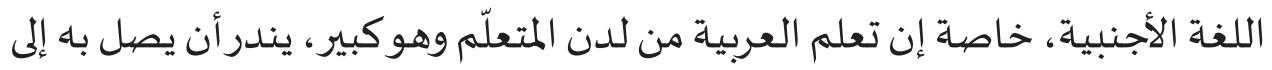
مستوى العرب عند ممارسته مهارة الكلام

7- التدرج : ينطق مبدأ التدرج هنا أيضا.. إن الكلام، كما قلنا، مهارة مركبة ونشاط عقلي

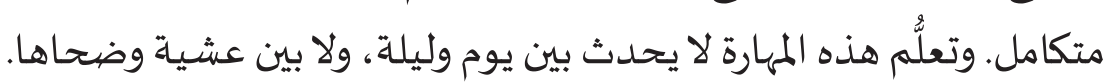

\section{طريقة تعليم مهارة الكلام}

الطريقة في تعليم مهارة الكلام هى النظام الذى يسير عليه المعلم فى إلقاء الدرس ليوصل الممعلومات إلى أذهان الطلاّب بشكل يحقق أغراض التربية.'v

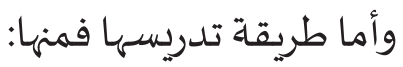

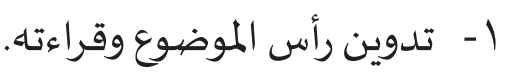

r- مناقشة التلاميذ بهدف توضيح جوانب الموضوع وتحديد أهم عناصره وخصهوصها في المراحل الأولى في تعليم التعبير.

r- مطالبة التلاميذ بالحديث في كل عنصرمع التوجياء. ع- حديث التلاميذ عن الموضوع.

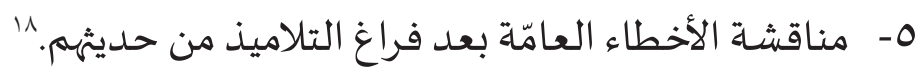

وقال محمد الخطيب »أن طريقة تعليمهاهنها: السؤال والجواب، وتدريب التلاميذ على الملاحظة وإدراك العلاقةن ويعرض المعلم إلى التلاميذ صهورالأشكال ويطلب من التلاميذ التهابل

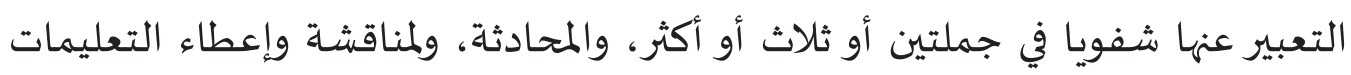

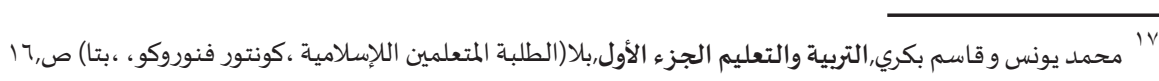

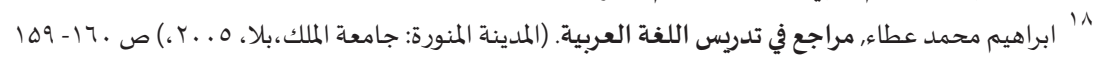




\section{وسـائل مهارة الكلام}

إنّ من أهم الوسـائل والأجهزة التي تفيد الدارس على تعلم مهارة الكلام هي اللوحات الوبرية، والصور العادية والشفافة والأفلام الثابتة، ومعامل اللغاته.” وإنّ المعينات البصرية المستخدمة في أنشطة الكلام مثل الرحلات الميدانية والألعاب اللغوية والمعينات مثل لوحة العرض، واللوحة الوبرية وقرص الساعاة، والصور والشرائح والأفلام الشريطية الثابتةه.

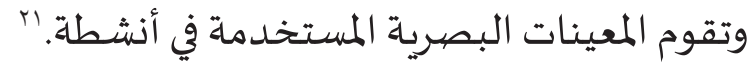
بعض الوسائل التعليمية لتعلم مهارة النطق والكلام:

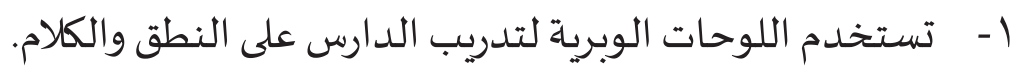
r- - تستخدم الأفلام الثابتة في عرض منظم لسلسلة من الاطارات أو الصور التي تعين

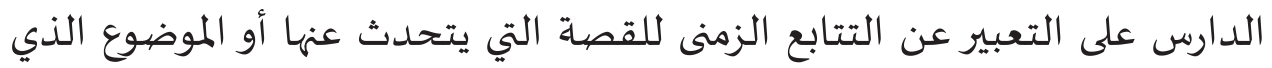

يدرساه.

r- تستخدم الصور المفردة و الصور المتسلسلة المصاحبة لحوار معين بهدف تقريب يلمبل المعنى عند الدارس.

ع- يستخدم أيضا قرص الساعة لتعليم الدارسين الوقت، والملصقات والبطاقات

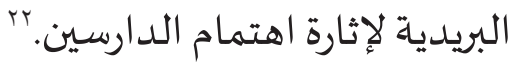

\section{اختبار مهارة الكلام}

تهدف اختبارات الكلام إلى قياس قدرة الطالب على الكلام بمستوياته المختلفة، وقد تكون

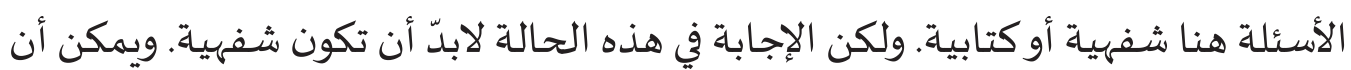
تكون القدرة الكلامية ذات ثلاثة مستويات على الأقل: مستوى النطق ثم مستوى تكوين

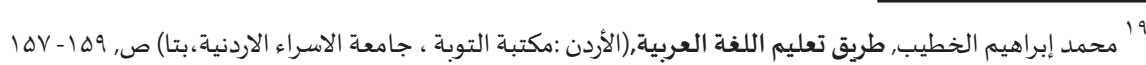

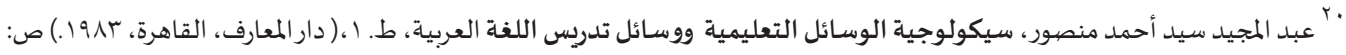

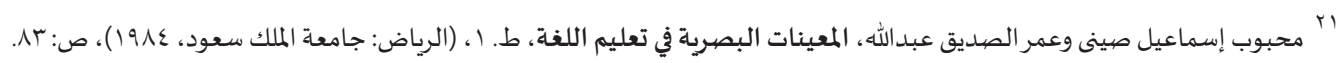

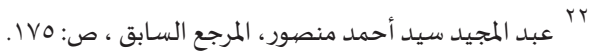


الجملة ثم مستوى تكوين الكلام المتصل. ومن وسـائل قياس القدرة الكلامية: اختبار الأسئلة

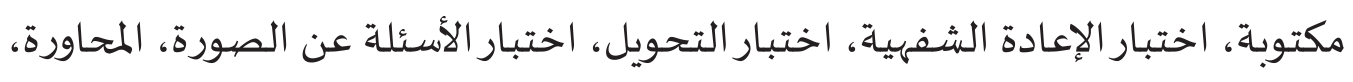

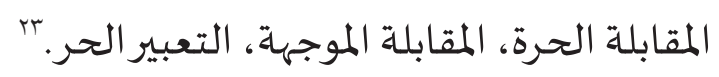

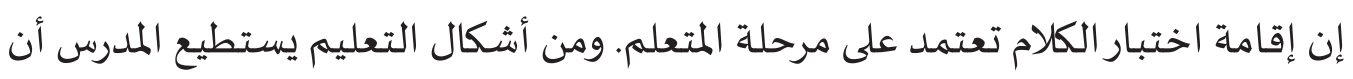
يستعمل بالطريقة الرادعة أو بالطريقة الحرة. الطريقة الرادعة مثل الاختبار بالقصية. وأما

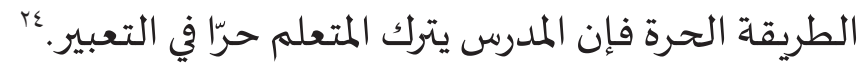

\section{المبحث الثاني : أسلوب المناقشـة مفهوم أسلوب طريقة المناقشة}

وهو من الطرق الفعّالة في تدريس اللغة العربية بحيث تنمّي معلومات التلاميذ وثروتهم اللغوية، وتحثّهم على البحث والاطلاع، وتكسبهم مهارة المناقشّة والرغبة في التعبيرعن رأيهم وحسن عرض وجهة نظرهم. ro r. وقال رياض العارف الحيّان إن المناقشـة كالطريقة الحوارية هي طريقة تفاعلية وتختلف عنها

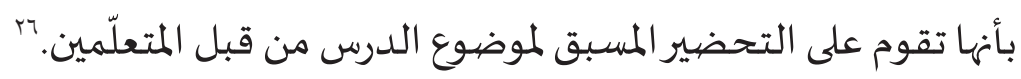
هوأسلوب قديم في التعليم يرجع للفيلسوف 》سقراطياط لتوجيه فكر تلاميذه وتشجيعهم

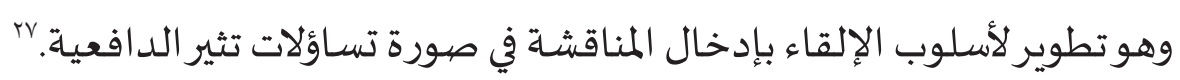

المهمّات التي يجب على المعلم أن يراعيها في عملية المناقشـة : ا - التخطيط السليم للدرس، بحيث تنصب المناقشة حول أهداف الدرس r - ضرورة اهتمام المعلم بالفروق الفردية ، وإتاحة فرصية المناقشـة والمشاركة.

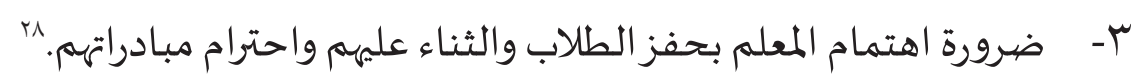

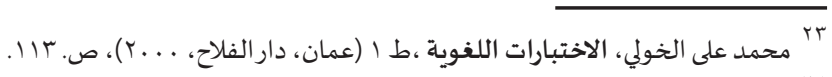

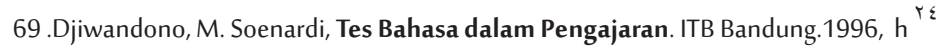

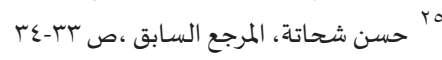

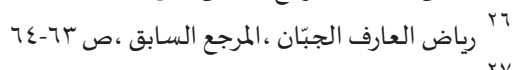

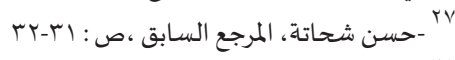

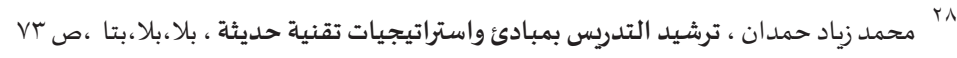


ا - مناقشة تلقينية : وتعتمد على السؤال والجواب

r- المناقشّة الإكتشافية الجدلية :وتعتمد على أسئلة تقود إلى الحلول الصحيحة وإثارة

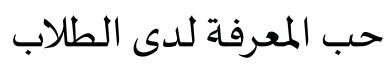

r- المناقشة الجماعية الحرة : وفيها يجلس مجموعة من التلاميذ على شكل حلقة.

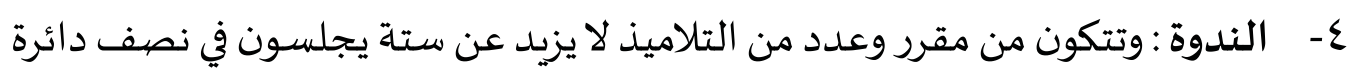

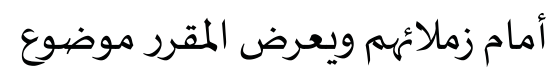

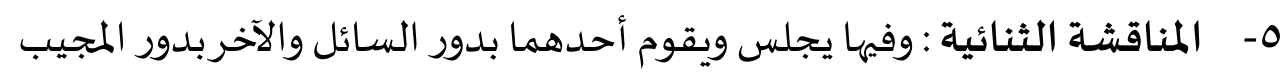

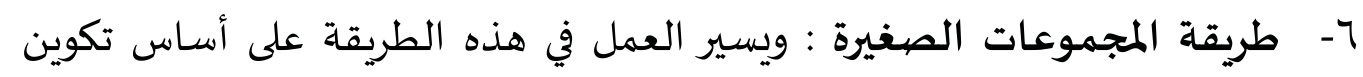

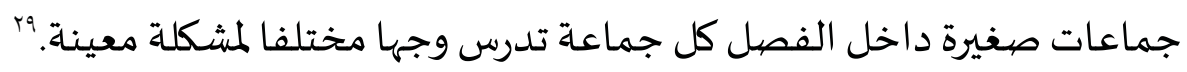

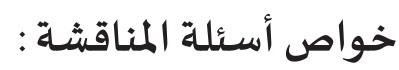

1- أن تدور الأسئلة حول حقائق سبق للتلاميذ تعلّمها.

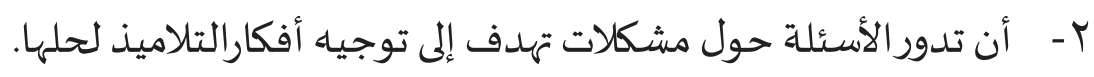
ب- ينبغي أن تتحدى الأسئلة تفكيرالتلاميذ شريطة أن تكون في مستواهم العقلي .

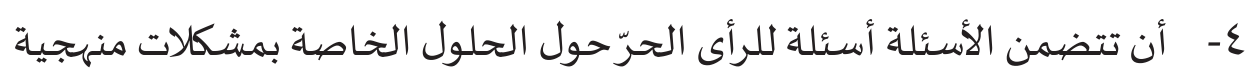
0- أن يكون السؤال واضحا بسيطا موجزا في صياغته .

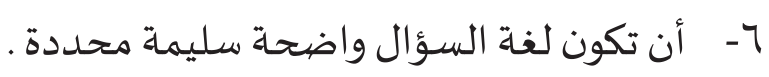

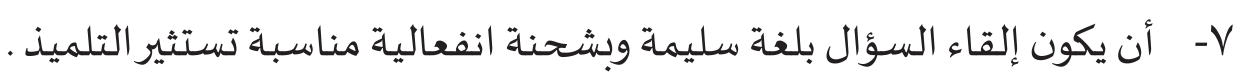

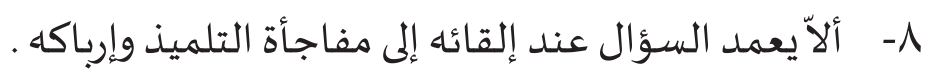
9- أن توزّع الأسئلة توزيعا عادلا على أساس عشوائي .

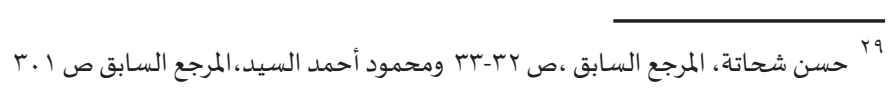


• ا - أن تتنوع الأسئلة لتستثير معارف قديمة سبقت دراستها. r

\section{إيجابيات طريقة المناقشـة :}

ا - المناقشة تجعل الطلاب مشـاركين فعالين في الدرس. إن مذا الأسلوب في التدريس يستثير قدرات الطلاب العقلية T- ب أن الطلاب الذين يشاركون في الدرس يشعرون بقيمة العلم . ع- ينمي هذا الأسلوب في الطلاب عادة احترام آراء الآخرين ، وتقدير مشاعرهم 0- يساعد الطلاب على تعويدهم على مواجهة المواقف . 7- يساعد الطلاب على جمع أكبر عدد من المعلومات عن الموضوع. -V - - شعور الطالب بالفخروالاعتزازوهو يضيف الى رصيد زملائه المعرفي N9- يساعد هذا الأسلوب على تقارب آراء الطلاب وأفكارهم. • ـ - تساعد هذه الطريقة على تنمية المعلم من خلال التغذية الراجعة . ا | - تساعد الطلاب من خلال تنمية روح العمل الجماعي. r ا - يفيد هذا الأسلوب تربويا في تعويد الطلاب على ألاّيكونوا متعصبين لآرائهم ومقترحاتهم

\section{سلبيات طريقة المناقشـة :} ا - إذا لم يحدّد المعلم موضيوعاه جيّدا ، فقد تختلط عليهاه الأمور . r - الوقت قد يسرق الجميع ما لم ينتبه إليه المعلّم. ب- إذا لم يحدّد المعلم أهداف درسـه جيّدا منذ البداية ، فقد يضيع منه الطريق . ع- قد تسيطر مجموعة من الطلاب على إذا لم ينتبه المعلم لذلك.

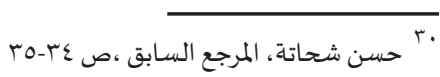


0- هذا الأسلوب قد يجرح مشـاعربعض الطلاب الذين يؤثرون الانطواء 7- إذا لم يستعد الطلاب للمناقشـة فان المناقشـة ستكون لا جدوى منها. V- إذا لم يضبط المعلم إدارة المناقشة فان الدرس سوف يتحول الى الفوضى . A- إذا لم يهتم المعلم بتسجيل وتلخيص أهم الأفكارفإنها قد تضيع الفائدة. ب

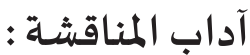

1 - سيادة النظام ، والبعد عن الفوضى في التعقيب.

ب - المجاملة واحترام الآراء وعدم تسفيهها.

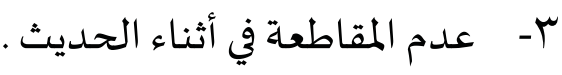

ع- عدم احتكار فرد واحد للكلام ،

0- وجوب إشراك سائر التلاميذ في المحادثة سواء بالاستماع أو المناقشة .

7- الابتعاد عن الانفعال والغضب في أثناء الكلام والردّ والتعقيب..بr

المبحث الثالث :أهمية قواعد اللغة العربية

معنى قواعد اللغة العربية

أنّ قواعد العربية تشمل في معناها الحديث عن كلّ علمي ( الصرف والنحو ) فالصرف مثلا يعني باللفظة قبل صوغها في الجملة ويبحث أيضا في حقلي الاشتقاق والتصريف. أما النحو فهو عملية تقنين القواعد والتعليمات التي تصف تركيب الجمل والكلمات وعملها في حالة

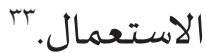

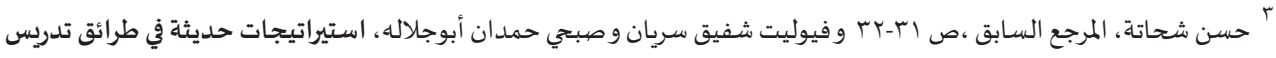

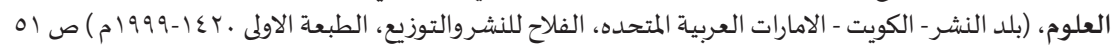
Di akses pada tanggal 20 desember 2011 ..http://tge.gov.sa/vb/showthread.php?t=3708

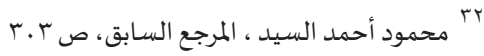

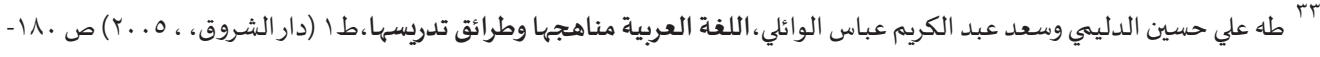




\section{أهداف تدريس قواعد اللغة العربية}

ا - ضبط حركات ما يكتب وما يلفظ، فتعصهم المرء من الخطاء النحوي. r - التربية العقلية، كانت دراسة النحو مفيدة في التربية العقلية . r- تكوين عادات لغوية صحيحة.

ع-نماء الذوقي الأدبي عن طريق أسلوب التعبير الأدبي عن بئهم وحاجاتهم. 0- تفهم صيغ اللغة واشتقاقها عن طريق تعليل القواعد النحوية والصرفية.؛؟

\section{طرق تدريس قواعد اللغة العربية} الطريقة الأولى: الاستقرائية وهي تعني بفكرة (تداعي المعاني) بالإفادة من المعلومات الماضية

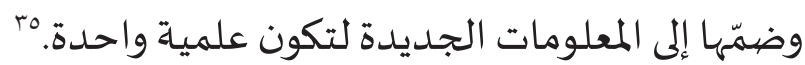
الطريقة الثانية: القياسية الاستنتاجية هي التي يتمّ بها انتقال الفكر من الحكم على الكلّي

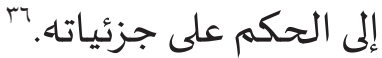
الطريقة الثالثة: الاستجوابية وهي التي تعتمد على سؤال الطلاب وإجاباتهم عن دقائق الموضوع الذي يعطونها واجبا بيتيا. الطريقة الرابعة: طريقة المحاضرات وهي تعتمد على حديث الأستاذ. الطريقة الخامسـة: الاقتضيائية وهي تدريس المدرس صلابة القواعد النحوية .

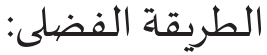
ا - البدء بالطريقة القياسية ثم الانتقال إلى ما بين الاستجواب والاستقراء والإلقاء r- البدء بالطريقة الاستقرائية.،

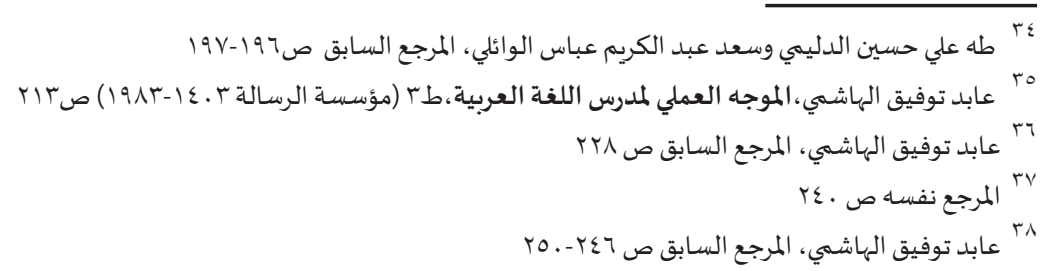




\section{الإرشادات في طريقة تدريس القواعد العربية:}

1 - تُكْتَب الأمثلة التي أعدها المدرس جلية على السبورة.

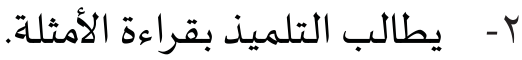

r- يسير المدرس في المناقشّة والاستنباط على النحو الذي شرحناه في الكتاب. ع- تُدَوَّن القواعد بعد استنباطها واضحة على السبورة. ه- تبَيَن وجوه المشابهة أو المقابلة بين موضيوع الدرس الجديد وموضهوع أي درس سابق كلما كان ذلك مفيداً.

7- يُطلب إلى التلاميذ تأليف جمل كثيرة تنطبق على التعاريف والقواعد التي استنبطوها. V- تربط دروس القواعد بدرس الإنشـاء كأن يكون موضيوع التمثيل في دروس القواعد أحياناً موضوعاً إنشائيًّا..

\section{المبحث الرابع : منهج البحث ومدخله}

اختار الباحث في هذا البحث البحث التجريبي بالمدخل الكمي ، وهو يحاول هذا البحث أن

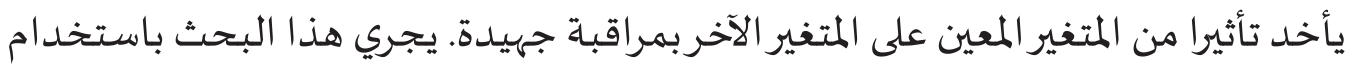
الاختبار القبلي و الاختبار البعدي لفصل التجربة. والأسلوب المستخدم لهذا البحث هو

الإحصياء التائي ( T-tes). فعالية تنمية مهارة الكلام بأسلوب المشاركة ستظهر في الاختبار القبلي و الاختبار البعدي لفصل الثاني العالي الديني (فصل التجربة).

\section{مجتمع البحث وعينته وأسلوب اختيارها}

الميدان في هذا البحث هو المدرسة العالية بمعهد 》السنيّة بكنشونج - جمبر. واختار الباحث بهذا الميدان لأنّ هذه المدرسـة مفتوحة لعملية البحث العلمي، أما عينة هذا البحث فهو جميع طلاب الفصل الثاني العالي السنة الدراسية في مدرسة

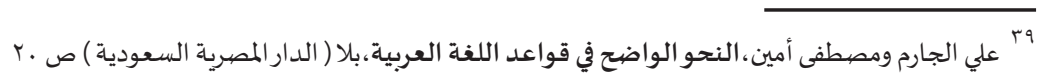


"السنيّّة)بكنشونج - جمبر ، فهي • ب طالبا ،وتلك العينة اختارها الباحث لفصل التجرباة. وهذه المدرسـة - أيضيا - من المدارس التي تستخدم اللغة العربيّة كمنهج الدراسي في عملياة التعليم ولم تستخدم تنمية مهارة الكلام بأسلوب المشاركة في الحجرة الدراسية. ولذلك اراد الباحث أن يجري الدرا سـة العلميّة فيها.

$$
\text { متغيرات البحث }
$$

متغيرات البحث التي استطاع الباحث أن يصل إليها تنقسم كالتالي: ا - المتغير المستقل في هذا البحث تطبيق أسلوب المناقشة لتنمية مهارة الكلام. r - المتغير التابع في هذا البحث هو نتيجة التعلم لدي الطلبة قبل عملية التجربة وبعدها. ب- - مت المتغير الضابط

\section{المتغير الضيابط في هذا البحث هو:}

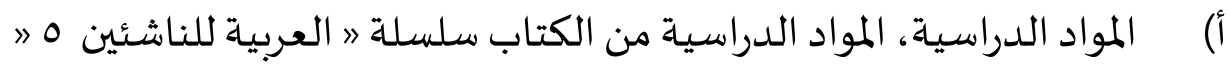
ب) المعلم، المعلم في هذا البحث هو الباحث نفسـ. ت) الوقت،وقت الدراسة يوم السبت الخصية الثالثة لفصل التجربة. ث) وسسائل الدراسـة، وسائل الدراسـة التي يستخدمها الباحث هي المسجلات ، البطاقات

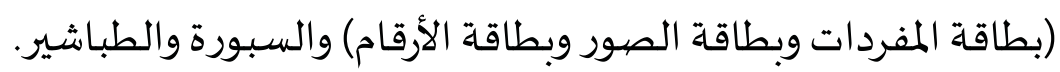

$$
\begin{aligned}
& \text { أدوات البحث } \\
& \text { الأدوات التي استخدمها الباحث لجمع البيانات هي: }
\end{aligned}
$$

هي المراقبة والتدوين للحوادث الواقعة فى الموضوع المتعلق بالغرض. ثهذه الطريقة يلاحظ

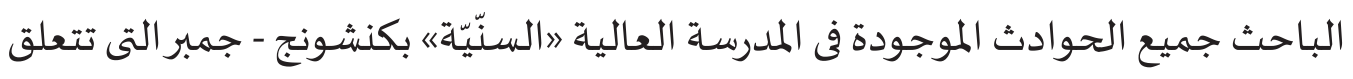

¿ Sutrisno Hadi, Metodologi Research II (Jogjakarta: Rineka Cipta, 1996), hal. 136 
بأسلوب المشاركة فهها. ويقوم الباحث أيضا بهذا الإجراء للحصول على البيانات التي تتعلق

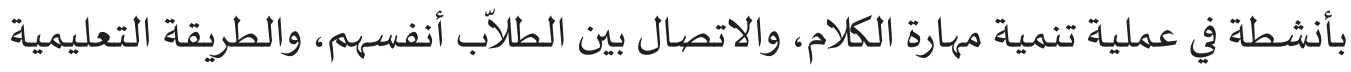
المستخدمة ومشاركة الطلاّب في عملية تنمية مهارة الكلام بأسلوب المشاركة. وتقام هذه الفالها الملاحظة من خلال عملية التعليم المباشرة.

\section{ب ابمقابلة (Interview)}

هي طريقة جمع الحقائق والمبحوثين وجها لوجهاه لحصول المعلومات من مصادرها.' ويقوم

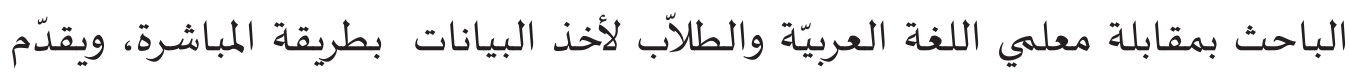

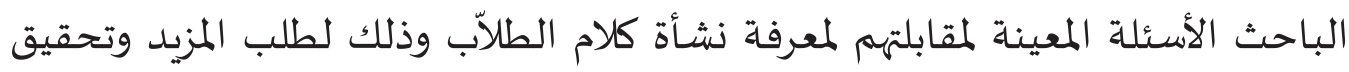

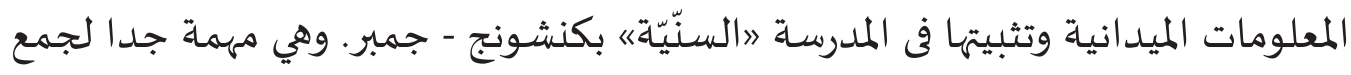
المعلومات من مصدرها المباشرة بطريقة السؤال والجواب.

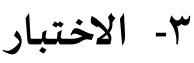
الاختبارهو الوسيلة أوالإجراء أوالأنشطة المركبة لمعرفة قدرة الشخص التي تعكس الكفاءة

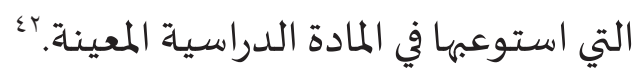

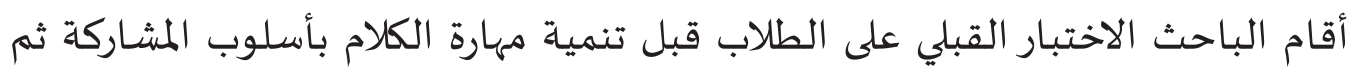

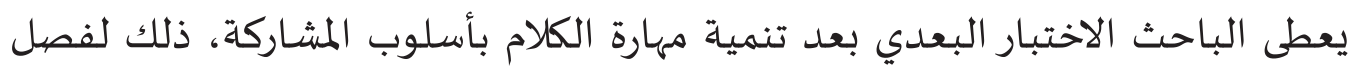

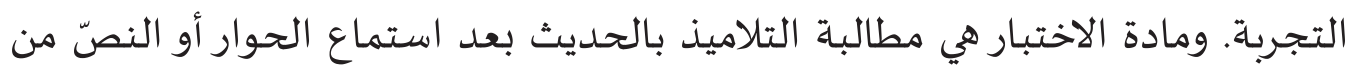

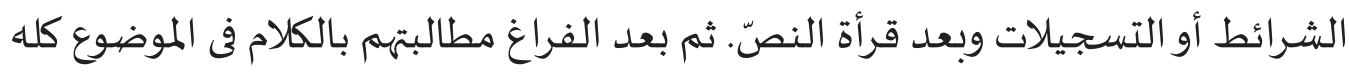

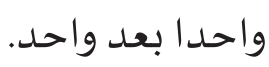

\footnotetext{
¿) Margono, Metodologi Penelitian Pendidikan, (Jakarta: Rineka Cipta), hal. 165

¿r M. Soenardi Djiwandono. Tes Bahasa dalam Pengajaran.( ITB Bandung. . 1996 M), Hlm. 1
} 


\section{المبحث الخامس : عرض بيانات المقابلة وتحليلها ومناقاشتها عرض بيانات المقابلة مع معلّم اللغة العربية} قابل الباحث بعد التجربة في الفصل أحد معلمي اللغة و تحادث معاه حول درس اللغة العربية وطريقة تدريسها والمشكلة التي تواجه الطلاب ورأيه في تدريس مهارة الكلام وتنميتها بأسلوب المشاركة بطريقة المناقشـة . وقال أحد معلمي اللغة أن اللغة العبية درست في المستويات الثلاثة كلها ، ولا توجد الطريقة الخاصة في تدريس اللغة العربية، والطريقة المستخدمة الآن هي طريقة القواعد والترجمة، والقراءة، والنص الحواري. أما المشكلات التي تواجه الطلاب فمنها ضعفهم في

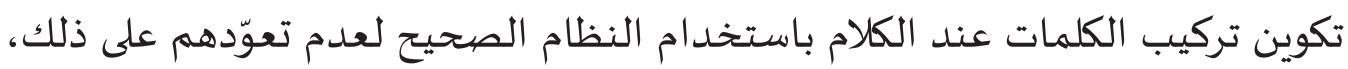

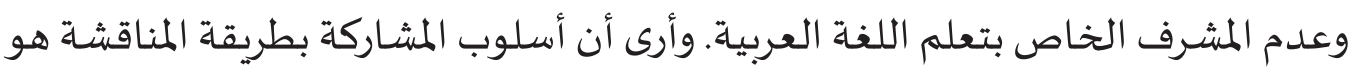

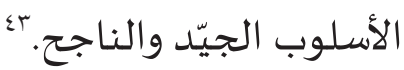

\section{عرض بيانات المقابلة مع بعض الطلاب} وأما بعض الطلآب فقالوا بأن هذا الأسلوب يؤثّر كثيرا في تطبيق القواعد العربية في أداء الكلام، وهويؤدّي إلى الكلام متزوّدا بالقواعد العربية والمفردات وكذلك يؤثّر كثيرا في الدافعية والرغبة في الكلام وبالنسبة للمفردات قد ازدادت بالمفردات الجديدة المستخدمات في النصوص العربية وبالمفردات المستخدمة أثناء المناقشَة من قِبل بعض الطلاب، وبعضهم يقول أنّ هذا الأسلوب يورث أيضيا الطلاقة في الكلام لأنّ الطلاقة كثرحصهولها بالتعويد على ميلى أداء الكلام، ورأى البعض الأخرومن المشـاكل في أداء الكلام ضعف تكوين الكلمات والجمل وهذا أسلوب المشاركة يساعد كثيرا في إزالة ذلك.

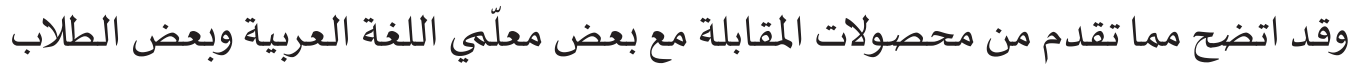

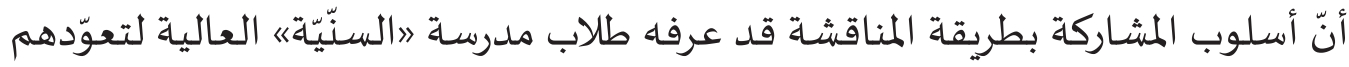
على ذلك الأسلوب، وأنه لم يسبق تطبيقه وإجراءاته في المدرسـة العالية من قبل، وأنها يؤثر جيدا في الدافعياة والشجاعة والرغبة لدى الطلاب في الكلام ويكثرثروة المفردات الجديدة

$$
\begin{aligned}
& \text { "r "ح حصول المقابلة مع بعض معلمي اللغة العربية، في إدارة المعهد والمدرسة، }
\end{aligned}
$$

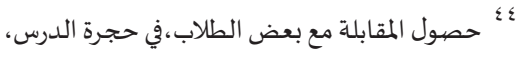


المستخدمة في النصوص العبية والكلام. وأنّ بعض الطلاب قبل تطبيق هذا السلوب يشعر بالخوف من الخطأ في الكلام وتكوين الكلمات ولكن بعد تطبيقه لايخاف من الخطأ في الكلام ويتّضح من هذه المعلومات وهذا التحليل أنّ هذا الأسلوب يؤثّر إيجابيا في تنمية مهارة الكلام.

\section{خلاصة}

إن تدريس مهارة الكلام بأسلوب المشاركة بطريقة المناقشـة ينمي نطق الحروف من مخارجها

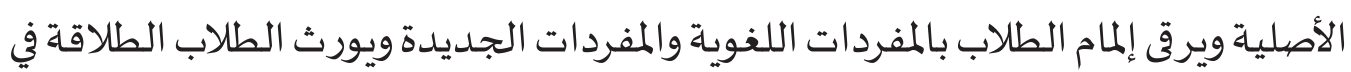
أداء الكلام. لذا هذه الطريقة يسهّل على الطلاب تطبيق القواعد العربية في الكلام وتطويره. بجانب تلك المزايا ترقي هذه الطريقة كفاءة الطلاب في استخدام النظام الصحيح لتركيب الكلمات العربية عند الكلام وينشيئ شجاعة لدى الطلاب ويزيد من دافعيتهم في أداء الكلام.

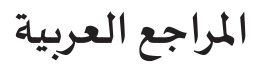

الخطيب، محمد إبراهيم، طريق تعليم اللغة العربية,(الأردن :مكتبة التوبة ، جامعة

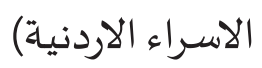

الدليمي، طه علي حسين وسعد عبد الكريم عباس الوائلي، اللغة العربية مناهجها وطرائق

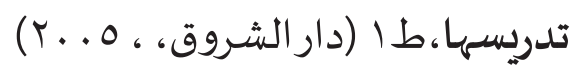

الدين، صلاح. تدريس اللغة العربيّة بالمرحلة الإبتدائية، أسسـه وتطبيقاته، ، الكويت.

$$
\text { للمطبعة النشروالتوزيع.ع ع } 9 \text { ا م). }
$$

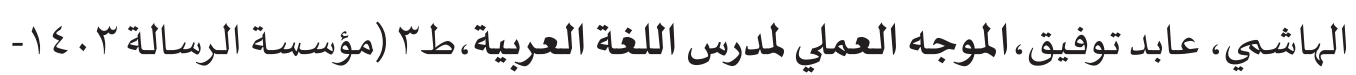

$$
\text { (19人r }
$$

الناقة، فتحي علي يونس ومحمود كامل، أسـاسيات التعليم اللغة العربية،ط ا (قاهرة :

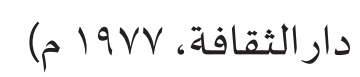

الناقة، محمود كامل ورشدي أحمد طعيمة ، طرائق تدريس اللغة العربية لغير الناطقين

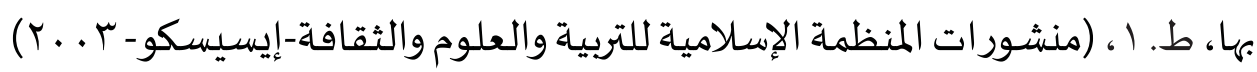

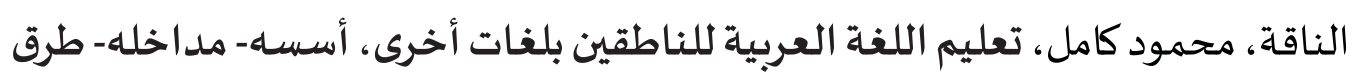




$$
\text { تدريسـ، ط. 1، (الرياض: الجامعة أم القرى، } 1910 \text { ) }
$$

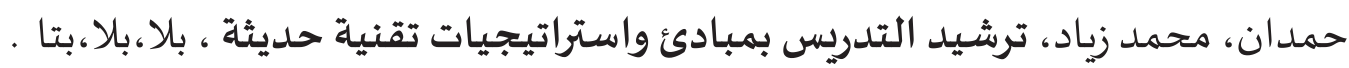

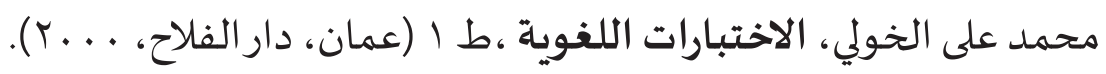

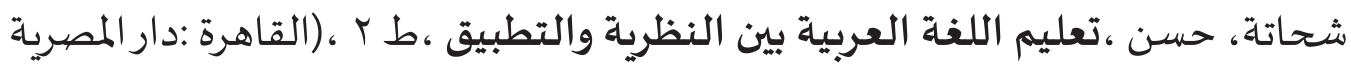

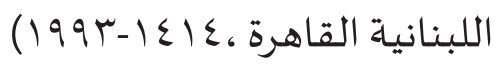

صابر، مجي الدين، قضايا نشر اللغة والثقافة الغربية الإسلامية في الخارج، المجلة العربية

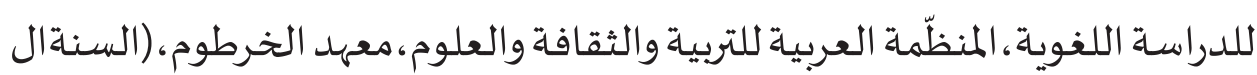

$$
\text { أولى، العدد الاول، اغسطس لمسكوبه } 91 \text { ). }
$$

صينى، محبوب إسماعيل وعمر الصديق عبدالله، المعينات البصرية في تعليم اللغة، ط. البه.

$$
\text { | ، (الرياض: جامعة الملك سعود، ع ع 191). }
$$

عطاء، ابراهيم محمد, مراجع في تدريس اللغة العربية. (المدينة المنورة: جامعة الملك،بلا،

$$
\text { (Y... }
$$

عليان، أحمد فؤاد، المهارات اللغوية ماهيتها وطرائق تدريسها، طا ، (الرياض:دار السلم، .$(1994$

مدكور، على أحمد، تدريس الفنون اللغة العربية، ط. ا، (القاهرة: دار الفكر العربي، . (. . r

مصطفى، إبراهيم والآخرون، المعجم الوسيط، ط.r.ج.ج، (تركيا: المكتبة الإسلامية، (19VY

منصيور، عبد المجيد سيد أحمد، سيكولوجية الوسـائل التعليمية ووسائل تدريس اللغة

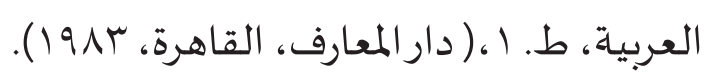

\section{المراجع الأجنبية}

Djiwandono, M. Soenardi. 1996. Tes Bahasa dalam Pengajaran. Bandung: ITB. Margono, Metodologi Penelitian Pendidikan, t.t. Jakarta: Rineka Cipta.

Nurhadi, dkk. 2004. Pembelajaran Kontekstual dan Penerapannya dalam KBK. Malang: Universitas Negeri Malang.

Sutrisno Hadi. 1996. Metodologi Research II. Jogjakarta: Rineka Cipta. 